\title{
Biochemical and Hemodynamic Changes in the Hypertrophied Dog Heart Subjected to Chronic Protein-Galorie Malnutrition
}

\author{
Koichi Tabayashi, Atushi Iguchi, Satoru Arai, \\ Yoshinito Sekino, Yoshimasa Moizumi and Togo \\ HORIUCHI \\ Department of Thoracic and Cardiovascular Surgery, \\ Tohoku University School of Medicine, Sendai 980
}

\begin{abstract}
Tabayashi, K., Iguchi, A., Arai, S., Sekino, Y., Moizumi, Y. and Horiuchi, T. Biochemical and Hemodynamic Changes in the Hypertrophied Dog Heart Subjected to Chronic Protein-Calorie Malnutrition. Tohoku J. exp. Med., 1987, 151 (4), 453-463 B Biochemical and hemodynamic changes were assessed in 13 dogs subjected to sub-coronary valvular aortic stenosis and chronic protein-calorie malnutrition (PCM). Red blood cell, hemoglobin, serum albumin, free fatty acids, blood glucose, cholinesterase and blood amino acid levels were measured. The dynamic geometry of the left ventricle (LV) was assessed with chronically implanted sonomicrometric piezoelectric crystals. Cardiac function was evaluated by mean velocity of circumferential fiber shortening (mean $\mathrm{VcF}$ ) and the relationship between LV end-systolic pressure (LVESP) or LV wall stress (LVWst) and LV end-systolic diameter (LVESD). The following results were obtained: 1) A decrease in body weight and increases in free fatty acids and 3-Methylhistidine were observed following long-term PCM. 2) Mean VcF was not depressed in dogs subjected to PCM. 3) The relationship between LVESP or LVWst and LVESD shipted downward and to the right after PCM, indicating reduced myocardial contractility. These findings suggest that the left ventricle in hypertrophied dog hearts subjected to PCM retains normal pump function, despite a low state in the myocardium. protein-calorie malnutrition; sub-coronary aortic stenosis ; free acid ; 3-Methylhistidine ; myocardial contractility
\end{abstract}

Several investigators (Pittman and Cohen 1964; Blackburn et al. 1977 ; Heymsfield et al. 1978; Kyger et al. 1978; Abel et al. 1979) have studied the effects of protein-calorie malnutrition (PCM) on cardiac structure, size and function in both man and the experimental animal. Heymsfield et al. (1978) reported normal cardiac function in patients presenting with severe malnutrition, whereas Alleyne (1966) reported reduced cardiac output in both undernourshied adults and in children with Kwashiorkor. However, a consensus as to whether or not cardiac function is significantly depressed by PCM has not been reached.

Received February 3, 1987 ; accepted for publication March 7, 1987. 
Previous studies of the effects of nutritional deficiencies (Watanabe 1958; Kyger et al. 1978; Abel et al. 1979) on cardiac metabolism and performance were conducted on normal hearts but only a limited number of experiments in which these hearts were also subjected to pressure overload have been reported.

The purpose of this study was to evaluated biochemical and hemodynamic changes in the hypertrophied dog heart subjected to chronic protein-calorie malnutrition.

\section{Materials and Methods}

\section{Experimental preparation}

Thirteen mongrel dogs weighing approximately $7.0 \mathrm{~kg}$ each were divided into three groups: Group I - control $(n=5)$; Group II - pressure overload without PCM $(n=3)$; Group III - pressure overload with PCM $(n=5)$. Pressure overload to the left ventricle (LV) was induced in Groups II and III by creating sub-coronary aortic stenosis. Subcoronary aortic stenosis was performed via a right thoractomy by plicating the non-coronary sinus of Valsalva using pledgeted 3-0 polypropolyene sutures (Fig. 1).

Two pairs of sonomicrometric piezoelectric crystals were implanted in the LV through a left thoractomy at two weeks after plication of the non-coronary sinus of Valsalva. One pair was sutured to the anterior and posterior epicardial wall to obtain maximum transverse external diameter in the plane of the short axis. A second pair was implanted across the LV free wall thickness. The proximal segment of crystal leads were anchored in subcutaneous tissue so that non-invasive postoperative hemodynamics could be easily measured. Dimentional data were measured by a sonomicrometer (San-ei Instrument 4105, Tokyo).

Dogs in Groups I and II were fed approximately $300 \mathrm{~g}$ of control diet (Table 1). They received 70 to $100 \mathrm{Cal} / \mathrm{kg}$ and 5 to $8 \mathrm{~g} / \mathrm{kg}$ protein daily. Dogs subjected to PCM were fed 30 to $50 \mathrm{~g} / \mathrm{kg}$ of control diet for two weeks. PCM was started about two months after sub-coronary aortic stenosis was induced. They received as average daily intake of 13 to $14 \mathrm{Cal} / \mathrm{kg}$ and $1 \mathrm{~g} / \mathrm{kg}$ protein. Dogs in Group III were fed $0.13 \mathrm{~g} / \mathrm{kg} /$ day of a canine multivitamin preparation and $0.05 \mathrm{~g} / \mathrm{kg} /$ day of a mineral supplement with a volume of a water adequate to prevent depletion of vitamins and minerals during PCM.

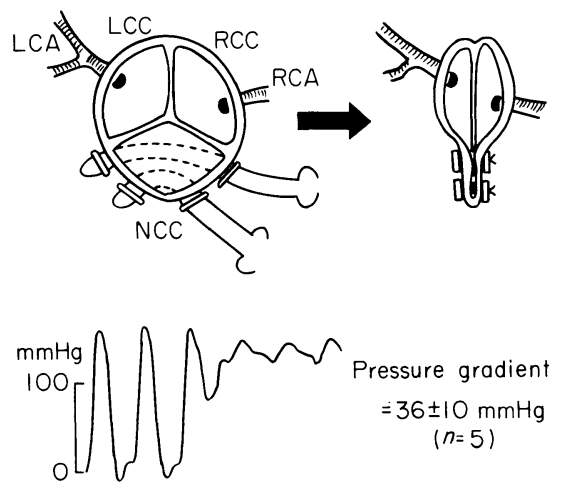

Fig. 1. Plication of the non-coronary sinus of Valsalva. Pressure gradient after obliteration of the non-coronary valvular sinus. LCA, left coronary artery; LCC, left coronary cusp ; RCC, right coronary cusp ; RCA, right coronary artery; NCC, non coronary cusp. 
TABLE 1. Composition of control diet

\begin{tabular}{|c|c|c|}
\hline \multicolumn{2}{|c|}{ Composition } & Content \\
\hline \multicolumn{2}{|l|}{ Calorie } & $351 \mathrm{Cal} / 100 \mathrm{~g}$ \\
\hline \multicolumn{2}{|l|}{ Water } & $7 \mathrm{~g} / 100 \mathrm{~g}$ \\
\hline \multicolumn{2}{|l|}{ Protein } & $27.2 \mathrm{~g} / 100 \mathrm{~g}$ \\
\hline \multicolumn{2}{|c|}{ Carbohydrate } & $7 \mathrm{~g} / 100 \mathrm{~g}$ \\
\hline \multicolumn{2}{|l|}{ Lipid } & $4 \mathrm{~g} / 100 \mathrm{~g}$ \\
\hline \multirow[t]{7}{*}{ Vitamin } & $\mathrm{A}$ & $1500 \mathrm{IU} / 100 \mathrm{~g}$ \\
\hline & $\mathrm{B}_{1}$ & $1.2 \mathrm{mg} / 100 \mathrm{~g}$ \\
\hline & $\mathrm{B}_{2}$ & $4 \mathrm{mg} / 100 \mathrm{~g}$ \\
\hline & $\mathrm{B}_{3}$ & $1 \mathrm{mg} / 100 \mathrm{~g}$ \\
\hline & $\mathrm{C}$ & $30 \mathrm{mg} / 100 \mathrm{~g}$ \\
\hline & $\mathrm{D}$ & $300 \mathrm{IU} / 100 \mathrm{~g}$ \\
\hline & $\mathrm{E}$ & $25 \mathrm{IU} / 100 \mathrm{~g}$ \\
\hline \multicolumn{2}{|c|}{ Folic acid } & $0.2 \mathrm{mg} / 100 \mathrm{~g}$ \\
\hline \multicolumn{2}{|c|}{ Choline } & $125 \mathrm{mg} / 100 \mathrm{~g}$ \\
\hline \multicolumn{2}{|l|}{ Inositol } & $50 \mathrm{mg} / 100 \mathrm{~g}$ \\
\hline \multicolumn{2}{|l|}{ Biotin } & $0.02 \mathrm{mg} / 100 \mathrm{~g}$ \\
\hline \multicolumn{2}{|l|}{ Niacin } & $8 \mathrm{mg} / 100 \mathrm{~g}$ \\
\hline \multicolumn{2}{|c|}{ Pantothenate } & $7.5 \mathrm{mg} / 100 \mathrm{~g}$ \\
\hline \multicolumn{2}{|l|}{$\mathrm{Ca}$} & $1.06 \mathrm{~g} / 100 \mathrm{~g}$ \\
\hline \multicolumn{2}{|l|}{$\mathrm{P}$} & $0.84 \mathrm{~g} / 100 \mathrm{~g}$ \\
\hline \multicolumn{2}{|l|}{$\mathrm{Mg}$} & $0.22 \mathrm{~g} / 100 \mathrm{~g}$ \\
\hline \multicolumn{2}{|l|}{$\mathrm{Na}$} & $0.44 \mathrm{~g} / 100 \mathrm{~g}$ \\
\hline \multicolumn{2}{|l|}{$\mathrm{K}$} & $0.80 \mathrm{~g} / 100 \mathrm{~g}$ \\
\hline
\end{tabular}

\section{Biochemical assays}

Blood samples were taken before and after PCM. The following biochemical parameters were measured : red blood cell count (Coulter Counter Model-S, CC 800, Towa, Tokyo), hemoglobin (Coulter Counter Model-S), albumin (BCG method), free fatty acids (enzyme method), blood glucose (glucose oxidase method), cholinesterase (Weher Ellman method), blood amino acid content (amino acid analyzer).

\section{Hemodynamic studies}

Hemodynamic studies were performed in Group III prior to PCM and at two weeks after PCM. Dogs were anesthetized with thiamylal sodium. Ventilation was controlled by a Harvard constant volume respirator. A 7 Fr. Micro-tip catheter transducer (PG-360; Millar Instruments, Inc., Houstom, TX, USA) was inserted into the LV via the right carotid artery for measurement of LV pressure (LVP). Piezoelecric crystal leads previously anchored in subcutaneous tissue were exposed for measurement of dimensional data and LVP. These parameters were measured at rest and during the infusion of methoxamine (20 to $30 \mathrm{~g} / \mathrm{kg} / \mathrm{min}$ ). Left ventricular systolic pressure following the infusion of methoxamine increased 30 to $50 \%$ above baseline. Heart rate was controlled with atropine sulfate $(0.01$ to $0.02 \mathrm{mg} / \mathrm{kg}$ ).

Mean velocity of circumferential fiber shortening (mean $\mathrm{VcF}$ ) and left ventricular wall 
stress (LVWst) were calculated from the following equations :

$$
\begin{aligned}
& \text { mean } \mathrm{VcF}_{c}=\frac{(\text { LVEDD }- \text { LVESD })}{\mathrm{ET} \times \text { LVEDD }} \\
& \mathrm{LVW}_{\mathrm{st}}=\frac{\mathrm{LVP} \times(\mathrm{LVD}-\mathrm{LVWth})}{4 \times \mathrm{LVWth}}
\end{aligned}
$$

where : LVEDD = left ventricular end-diastolic diameter, ET=ejection time, LVD=left ventricular diameter, $\mathrm{LVW}$ th $=$ left ventricular wall thickness.

Dogs in Group III were sacrified at $95 \pm 4$ days (mean \pm s.D.) after creation of subcoronary aortic stenosis. Dogs in Group II were sacrificed at $94 \pm 18$ days.

LV weight and free wall thickness were measured. LV weight included the ventricular septum, papillary muscle, aortic and mitral valve. A biopsy specimen was taken from the LV free wall and fixed with $10 \%$ formalin. This tissue was stained with hematoxylin eosin $(\mathrm{H}$ and $\mathrm{E})$ and elastica Mason. Histologic examination was performed under light microscopy.

\section{Statistical analysis}

Results are expressed as a mean \pm S.D. The paired $t$-test was used for all statistical analyses. Differences were considered to be statistically significant at a $p$ value less than 0.05 .

\section{Results}

\section{Nutritional and biochemical changes}

Fig. 2 shows percent change of body weight (BW), red blood cell (RBC), hemoglobin $(\mathrm{Hb})$, albumin $(\mathrm{Alb})$, free fatty acids (FFA), glucose, cholinesterase $(\mathrm{ChE})$, and the ratio of banded amino acids to aromatic amino acids $(\mathrm{B} / \mathrm{A}) . \mathrm{BW}$, $\mathrm{RBC}, \mathrm{Hb}, \mathrm{Alb}, \mathrm{FFA}$, glucose, $\mathrm{ChE}$ and $\mathrm{B} / \mathrm{A}$ of dogs with AS before PCM were $9.7 \pm 0.3 \mathrm{~kg}$ (mean \pm s.D. $) 694 \times 10^{4} \pm 44 \times 10^{4} / \mathrm{ml}, 14.6 \pm 1.6 \mathrm{~g} / 100 \mathrm{ml}, 3.55 \pm 0.42 \mathrm{~g} /$ $100 \mathrm{ml}, 0.44 \pm 0.17 \mathrm{mEq} /$ liter, $88.2 \pm 17.5 \mathrm{mg} / 100 \mathrm{ml}, 642 \pm 122 \mathrm{IU}$ and $3.42 \pm 0.56$. All but $\mathrm{ChE}$ were within normal limits. Percent change of $\mathrm{BW}, \mathrm{RBC}, \mathrm{Hb}$ and Alb after PCM was $-17 \pm 4 \%(p<0.01$ vs. per-PCM $) ;-5 \pm 13 \%$ (NS); $-6 \pm$ $14 \%(\mathrm{NS})$ and $-2 \pm 25 \%$ (NS), respectively. FFA after PCM measured $65 \pm 73 \%$ $(p<0.01$ vs. pre-PCM). Glucose, ChE and B/A after PCM measured $20 \pm 85 \%$ (NS) ; $10 \pm 15 \%$ (NS) and $15 \pm 35 \%$ (NS), respectively. Fig. 3 shows changes in free amino acids in blood. The change in free amino acids is expressed as the ratio of concentration of pre-PCM free amino acids to concentration in post-PCM free amino acids. Alanine (Ala), valine ( Val), methionine (Met), isoleucine (Ile), leucine (Leu), tyrosine (Tyr), phenylalanine (Phe), ornitine (Orn), lysine (Lys), histidine (His), 3-methylhistidine (3-Methis), arginine (Arg), L-methylhistidine (L-Methis), carnosine (Car), tauline (Tau), thereonine (Thr), serine (Ser) and glycine (Gly) of dogs with AS before PCM were 466.8 \pm 163.6 nmole/liter $155.2 \pm$ 31.7 nmole/liter, $49.6 \pm 4.3$ nmole/liter, $44.9 \pm 11.8$ nmole/liter, $100.1 \pm 26.9$ nmole/ liter, $40.7 \pm 15.7$ nmole/liter, $50.2 \pm 15.1$ nmole/liter, $31.6 \pm 5.5$ nmole/liter, $122.5 \pm$ 47.1 nmole/liter, $\quad 81.3 \pm 15.9$ nmole/liter, $\quad 15.6 \pm 12.6$ nmole/liter, $162.6 \pm 55.0$ nmole/liter, $6.2 \pm 3.3 \mathrm{nmole} /$ liter, $924.6 \pm 539.4 \mathrm{nmole} / \mathrm{liter}, 99.0 \pm 17.9 \mathrm{nmole} / \mathrm{liter}$, $210.8 \pm 118.8$ nmole/liter, $121.0 \pm 38.1 \mathrm{nmole} /$ liter and $212.5 \pm 60.1 \mathrm{nmole} /$ liter, 

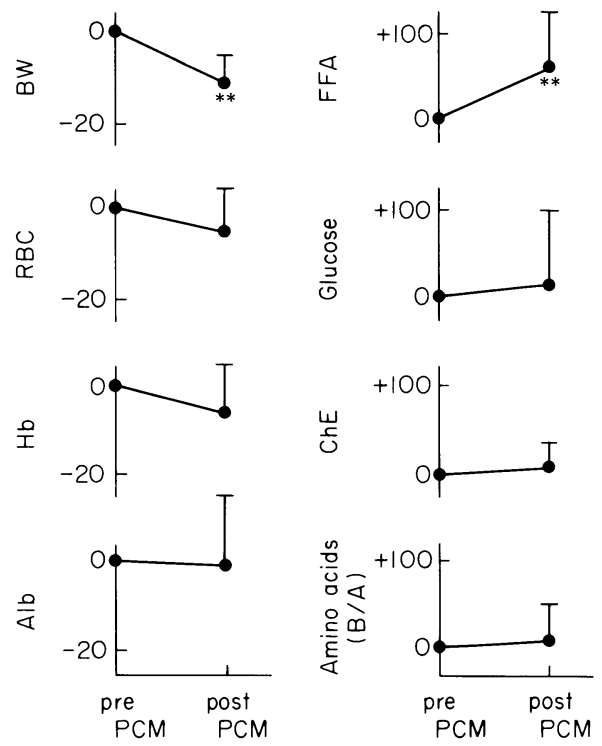

Fig. 2. Percent change of nutritional and biochemical parameters 14 days after protein-calorie malnutrition (PCM) in dogs with pressure overload (Group III). Values are expressed as means \pm s.D. ${ }^{* *} p<0.01$ vs. pre-PCM. $n=5$, $\mathrm{BW}$, body weight; RBC, red blood cell ; Alb, albumin ; FFA, fre fatty acid ; $\mathrm{ChE}$, cholinesterase; $\mathrm{B}$, banded amino acid; $\mathrm{A}$, aromatic amino acid.

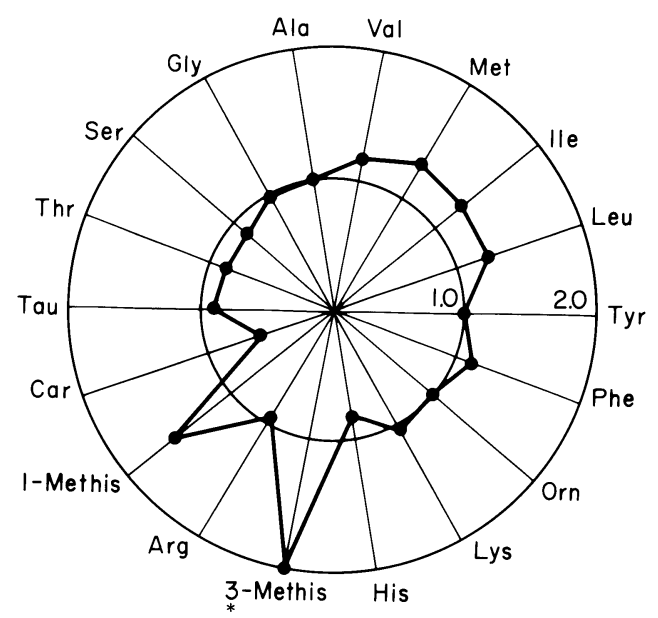

Fig. 3. Percent change of free amino acids measured in blood 14 days after protein-calorie malnutrition (PCM) in dogs with pressure overload (Group III). Values are expressed as the ratio of free amino acids measured pre-PCM to concentration levels measured post-PCM.

${ }^{*} p<0.05$ vs. pre-PCM. $n=5$. Ala, alanine; Val, valine; Met, methionine; Ile, isoleucine ; Leu, leucine ; Tyr, tyrosine ; Phe, phenylalanine; Orn, ornitine ; Lys, lysine ; His, histidine ; 3-Methis, 3-methylhistidine; Arg, arginine; L-Methis, L-methylhistidine; Car, carnosine; Tau, tauline; Thr, thereonine; Ser, serine; Gly, glycine. 
respectively. 3-Methylhistidine increased significantly after PCM. Concentration of additional free amino acids measured before and after PCM was not statistically significant.

\section{Hemodynamic changes}

The mean pressure gradient across the aortic valve at two months after creation of sub-coronary aortic stenosis was $36 \pm 10 \mathrm{~mm} \mathrm{Hg}$ (Fig. 1).

A linear relationship was found to exist between LVWSP or LVWst and LVESD (Fig. 4). The relation between LVESP and LVESD after PCM shifted downward and to the right. Slope decreased compared to pre-PCM measurements (Fig. 5). The relationship between LVWst and LVESD showed a trend similar to the relationship that was found between LVESP and LVESD. Mean VcF before and after PCM was $1.29 \pm 0.11$ and $1.46 \pm 0.09$, respectively. There were no significant differences.

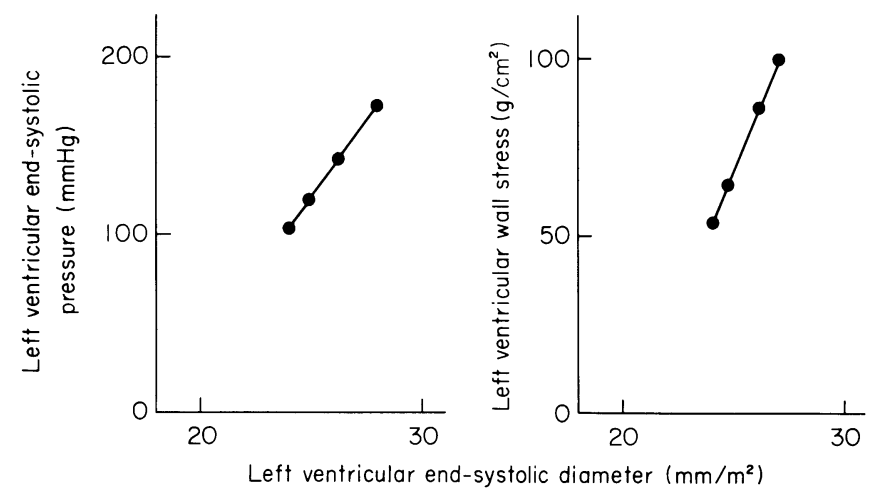

Fig. 4. Linear correlation between left ventricular end-systolic pressure or left ventricular wall stress and left ventricular end-systolic diameter.

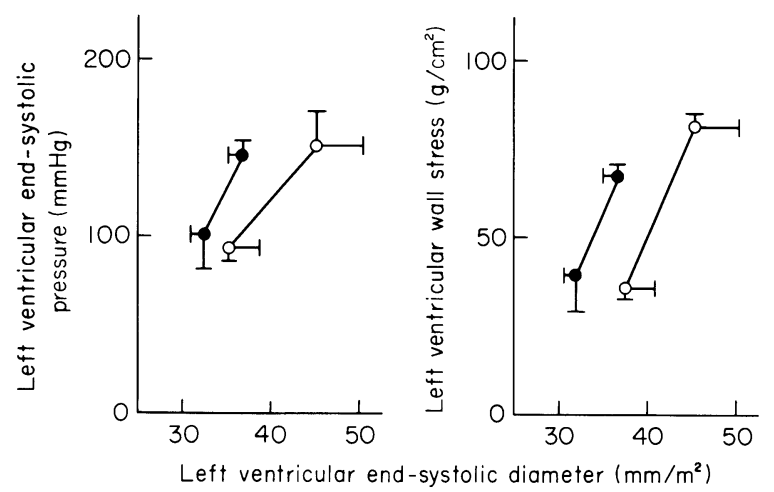

Fig. 5. Relationship between LVESP or LVWst and LVESD before $(\bullet-\bullet, n=$

$5)$ and after $(\bigcirc-0, n=5)$ protein-calorie malnutrition in dogs with pressure overload (Group III).

Values are expressed as means \pm s.D. 
TABLE 2. LV weight and wall thickness in Groups $I, I I$, and $I I I$

\begin{tabular}{lccc}
\hline & $\begin{array}{c}\text { Control } \\
\text { (Group I) }\end{array}$ & $\begin{array}{c}\text { Pressure } \\
\text { overload } \\
\text { without PCM } \\
\text { (Group II) }\end{array}$ & $\begin{array}{c}\text { Pressure } \\
\text { overload } \\
\text { with PCM } \\
\text { (Group III) }\end{array}$ \\
\hline BW & $9.7 \pm 0.3$ & $6.5 \pm 1.1^{*}$ & $10.2 \pm 0.6^{*}$ \\
LV weight & $43.4 \pm 1.9$ & $38.0 \pm 5.9^{*}$ & $55.7 \pm 3.3^{*}$ \\
LV weight/BW & $4.5 \pm 0.1$ & $5.5 \pm 0.5^{*}$ & $5.9 \pm 0.2^{*}$ \\
LV wall & $10.0 \pm 1.0$ & $12.0 \pm 0.8^{*}$ & $12.0 \pm 2.0^{*}$ \\
thickness & & & \\
\hline
\end{tabular}

Values are expressed as means \pm S.D.

* $p<0.05$ vs. control. LV, left ventricle; BW, body weight; PCM, protein-calorie malnutrition.

\section{Morphorgic and histologic changes}

The ratio of $\mathrm{LV}$ weight to body weight in Groups I, II and III was $4.5 \pm 0.1$ $\mathrm{g} / \mathrm{kg}, 5.5 \pm 0.5 \mathrm{~g} / \mathrm{kg}$ and $5.9 \pm 0.2 \mathrm{~g} / \mathrm{kg}$, respectively (Table 2 ). The ratio in Groups II and III was significantly higher than in Group I ( $p<0.05$ vs. Group I). The ratio of LV weight to body weight in Group III was higher than in Group II, but the difference was not statistically significant.

Fig. 7 shows light microscopy of LV myocardium in Groups I, II, III. An increase in volume of the myocytes and enlarged nuclei were observed in $\mathrm{LV}$ myocardium of Group II, indicating myocardial hypertrophy. Interstitial fibrosis and fatty infiltration were observed in Group III, but there was no evidence of atrophy, vacuolation or edema.

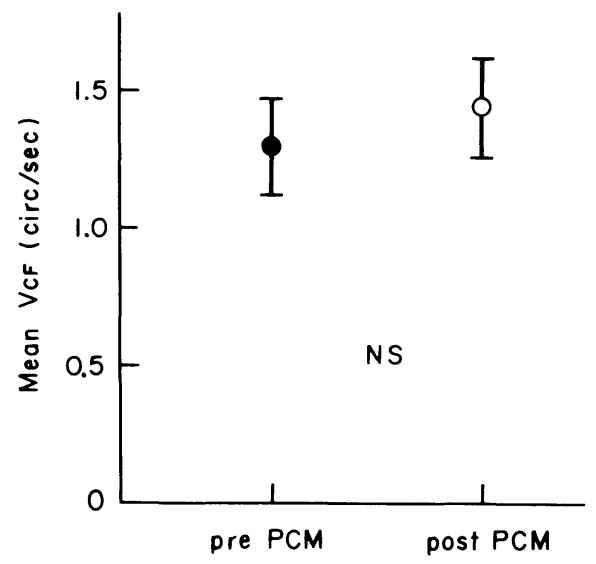

Fig. 6. Change in mean VcF before and after protein-calorie malnutrition in dogs with pressure overload (Group III). Values are expressed as means \pm s.D. mean $\mathrm{VcF}$, mean velocity of circumferential fiber shortening. $n=5$. 

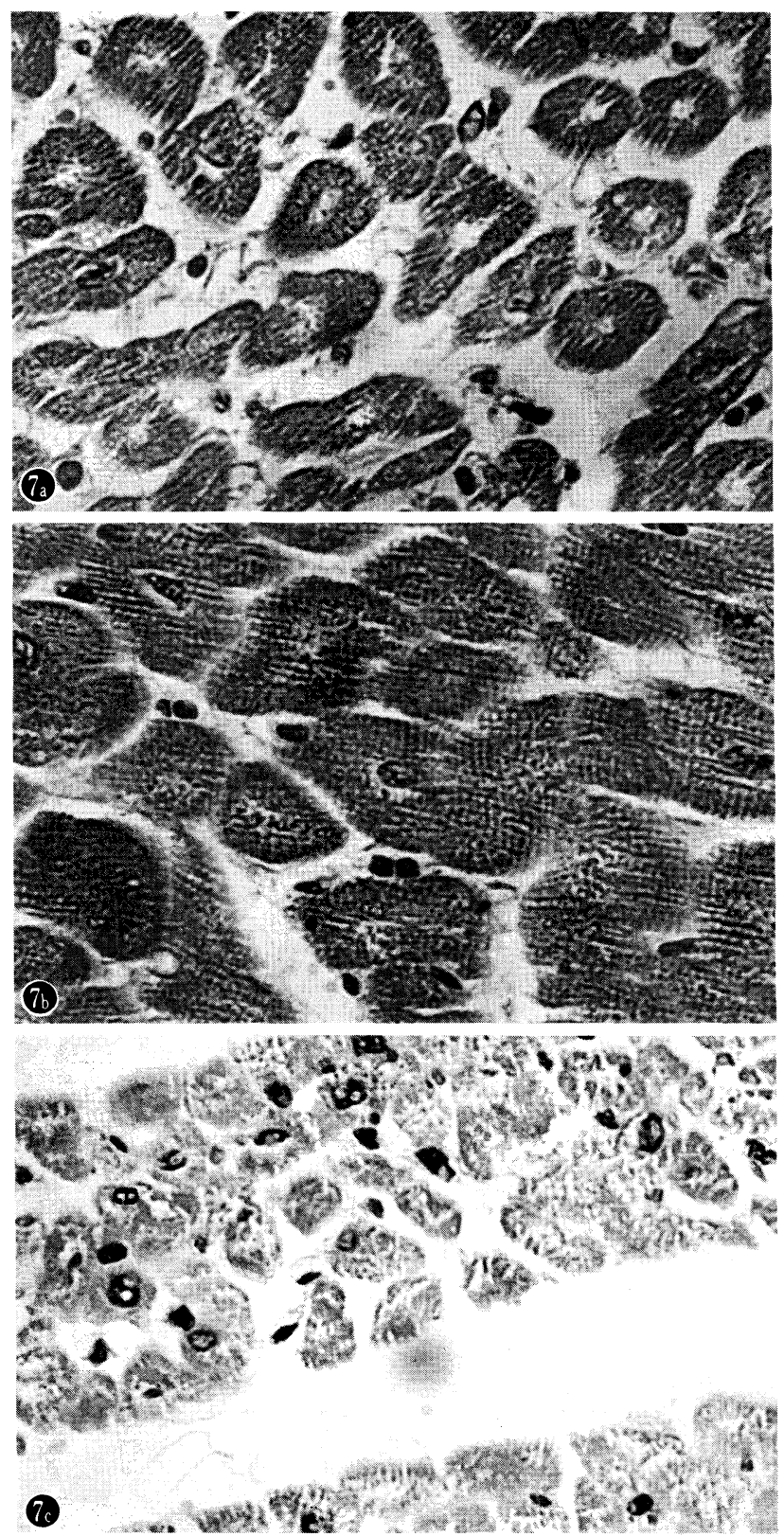

Fig. 7. Light micrograph of LV myocardium in groups I, II and III (hematoxylin eosin, $\times 200$ ). A, normal appearance of myofiber in a control dog (Group I); $\mathrm{B}$, myocardial hypertrophy in a dog with pressure overload (Group II). An increase in volume of the myocytes and enlarged nuclei are present. C, light micrograph of LV myocardium in a dog with pressure overload and proteincalorie malnutrition (Group III). Interstitial fibrosis and fatty infiltration are present. hematoxylin eosin $\times 150$. 


\section{Discussion}

Left ventricular (LV) hypertrophy has been experimentally induced by banding the ascending aorta (Sasayama et al. 1975; Malik and Geha 1977) but this method causes hypertension in the coronary arteries. Rembert et al. (1978) demonstrated that with supra-coronary aortic stenosis $52 \%$ of coronary blood flow occurs during systole in contrast to $5 \%$ which occurs with sub-coronary aortic stenosis. These findings indicate that experimentally induced aortic stenosis produces functional and metabolic changes at variance with clinical observations of patients presenting with aortic valvular stenosis. Roper et al. (1978) reported an experimental model of sub-coronary aortic stenosis which was induced by plicating the non-coronary sinus of Valsalva. Using a similar approach, we created sub-coronary aortic stenosis in puppies. The post-stenotic peak systolic pressure gradient across the aortic valve measured $36 \pm 10 \mathrm{~mm} \mathrm{Hg}$. Lv weight and wall thickness increased significantly compared to non-plicated control dogs.

It has been reported (Fanburg and Posner 1968) that LV hypertrophy can be recognized as early as 3 days after pressure overload and stabilizes within 7 days. Sasayama et al. (1977) demonstrated that cardiac contractility was not depressed after 18 days (range 13-24 days) of pressure overload. These findings are consistent with our model which produced a stable hemodynamic profile and showed that the heart could adapt to an extended period of pressure overload.

Body weight, hematocrit and hemoglobin were decreased by chronic proteincalorie malnutrition (PCM), whereas free fatty acids increased due to an elevated utilization of serum lipids. It has been reported (Ko and Paradise 1971 ; Blackburn et al. 1977; Heymsfield et al. 1978) that during a state of starvation that glucose is used as the primary energy source, then glycogen, and finally protein. When depletion energy and calories continue, protein is used as a source of glyconeogenic energy. 3-Methylhistidine is present in skeletal muscle, especially in myosin (Young and Munro 1978), and is excreted without re-utilization. These characteristics make it a useful indicator of the dissolution status of muscle protein.

Others have reported (Ko and Paradise 1971; Heymsfield et al. 1978 ; Kyger et al. 1978) that myocardial can use a wide variety of substrates as an energy source and that it has the ability to shift preferential food substances in order to sustain its metabolic needs. Therefore, the heart can utilize not only glucose, lactate, pyruvate, glycogen and lipid, but during a state of starvation can also utilize endogenous substrates (glycogen and triglyceride) (Ko and Paradise 1971). In fact, the ratio of $\mathrm{LV}$ weight to body weight in hypertrophied dog hearts with PCM was greater than it was in hypertrophied hearts without PCM. These results suggest that $\mathrm{LV}$ weight loss during a state of starvation was less than proportional weight loss in other organ. These findings are consistent with Chauhan's observation (1965) that three months of protein deficient diet in the 
monkey can cause a 15 percent reduction in cardiac weight and microscopic evidence of cardiac atrophy and fibrosis. However, these animals experienced a 20 percent loss in body weight and microscopic changes in skeletal muscle were more advanced than those in myocardium.

There have been several reports of protein-calorie malnutrition (Watanabe 1958; Kyger et al. 1978 ; Abel et al. 1979), but there is a paucity of data regarding cardiac function during PCM in dogs simultaneously subjected to chronic pressure overload. It has not been fully elucidated whether or not myocardial hypertrophy adversely effects myocardial function during PCM. It has been reported (Meerson 1962 ; Gudbjarnason et al. 1964) that pressure overload to the myocardium enhances uptake of amino acids and increases production of myocardial proteins resulting in myocardial hypertrophy and a gradual adaptation to pressure overload. However, oxygen and energy demands increase with left ventricular pressure overload and therefore, myocardial dysfunction may appear at an earlier stage of starvation. The degree of cardiac dysfunction in starvation may be the net result of factors diminishing or augmenting cardiac work (i.e., reduced blood pressure, decreased blood volume, and hypometabolism versus anemia and hypermetabolism.)

Cardiac function was evaluated using piezoelectric crystals implanted on myocardium. LV pump function was assessed by mean velocity of circumferential fiber shortening (mean $\mathrm{VcF}$ ), while $\mathrm{LV}$ myocardial contractivity was evaluated by establishing the relationship between LV endsystolic pressure or LV wall stress and $\mathrm{Lv}$ end-systolic diameter. Whether protein-calorie malnutrition is associated with depression of pump ability or myocardial contractility remains controversial (Heymsfield et al. 1978; Kyger et al. 1978; Abel et al. 1979). Heymsfield et al. (1978) reported that pump function and myocardial contractility were not depressed in patients with severe malnutrition. Kyger et al. (1978) demonstrated that myocardial contractility was depressed in protein deficient animals after an average of 48 days. Abel et al. (1979) showed that 50 days of a protein-calorie deficient diet in dogs caused a decrease in LV compliance and contractility. Mean VcF in Group III was not depressed after PCM which was probably due to anemia and hypermetabolism. On the other hand, myocardial contractility in Group III was depressed after PCM despite a shorter period of protein depletion and lower weight loss compared to results reported in previous studies. (Kyger et al. 1978; Abel et al. 1979). These findings suggest that pressure overload may exacerbate myocardial dysfunction and cardiac atrophy during PCM.

In conclusion, this study demonstrated an increase in free fatty acids in dogs subjected to chronic protein-calorie malnutrition with AS indicating enhanced utilization of serum lipids and that 3-methylhistidine can be a valuable indicator of profound catabolism. Myocardial contractility was depressed in malnourished dogs subjected to left ventricular pressure overload but cardiac pump function was 
well preserved.

\section{References}

1) Abel, R.M., Grimes, J.B., Alonso, D., Alonso, M. \& Gay, W.A. (1979) Adverse hemodynamic and ultrastructural changes in dog hearts subjected to protein-calorie malnutrition. Amer. Heart J., 97, 733-744.

2) Alleyne, G.A.O. (1966) Cardiac function in severely malnourished Jamaican children. Clin. Sci., 31, 553-562.

3) Blackburn, G.L., Gibbons, G.W., Bothe, A., Benotti, P.N., Harken, D.E. \& McEnany, T.M. (1977) Nutritional support in cardiac cachexia. J. thorac. cardiovasc. Surg., 73, 489-496.

4) Chauhan, S., Nayak, N.C. \& Ramalingaswami, V. (1965) The heart and skeletal muscle in experimental protein malnutrition in shesus monkeys. J. path. Bact., 90, 301-309.

5) Fanburg, B.L. \& Posner, B.I. (1968) Ribonucleic acid synthesis in experimental cardiac hypertrophy in rats. 1. Characterization and kinetics of labeling. Circulat. Res., 23, 123-135.

6) Gudbjarnason, S., Telerman, M. \& Bing, R. (1964) Protein metabolism in cardiac hypertrophy and heart failure. Amer. J. Physiol., 206, 294-298.

7) Heymsfield, S.B., Bethel, R.A., Ansley, J.D., Gibbs, D.M., Felner, J.M. \& Nutter, D.O. (1978) Cardiac abnormalities in cachectic patients before and during nutritional repletion. Amer. Heart $J .$, 95, 584-594.

8) Ko, K.C. \& Paradise, R.R. (1971) Effect of starvation on contractile response of isolated rat atria to citrate and bicarbonate free medium. Proc. Soc. exp. Biol., 137, $1115-1119$.

9) Kyger, E.R., Block, W.J., Roach, G. \& Dudrick, S.J. (1978) Adverse effects of protein malnutrition on myocardial function. Surgery, 84, 147-156.

10) Malik, A.B. \& Geha, A.S. (1977) Cardiac function, coronary flow and $\mathrm{MVO}_{2}$ in hypertrophy induced by pressure and volume overloading. Cardiovasc. Res., 11, 310316.

11) Meerson, F.Z. (1962) Compensatory hyperfunction of the heart and cardiac insufficiency. Circulat. Res., 10, 250-258.

12) Pittman, J.G. \& Cohen, P. (1964) The pathogenesis of cardiac cachexia. New Engl. J. Med., 271, 403-409.

13) Rembert, J.C., Kleinman, L.H. \& Fedor, J.M. (1978) Myocardial blood blow distribution in concentric left ventricular hypertrophy. J. clin. Invest., 63, 379-386.

14) Roper, K.O., Levitsky, S., Vorachek, M.A., Wright, R.N., Eckner, F.A.O. \& Feinberg, H. (1978) Development of a new model of subcoronary valvular aortic stenosis to create ventricular hypertrophy. J. surg. Res., 24, 302-307.

15) Sasayama, S., Ross, J., Jr., Franklin, D., Bloor, C.M., Bishop, S. \& Dilley, R.B. (1975) Adaptations of the left ventricle to chronic pressure overload. Circulat. Res., 38, 172178.

16) Sasayama, S., Franklin, D. \& Ross. J., Jr. (1977) Hyperfunction with normal inotropic state of the hypertrophied left ventricle. Amer. J. Physiol., 232, H418$\mathrm{H} 425$.

17) Watanabe, T. (1958) Myocardial metabolism in starved and hypoproteinemic dogs. Nippon Naika Gakkai Zasshi, 47, 90-102. (Japanese)

18) Young, V.R. \& Munro, H.N. (1978) N-methylhistidine (3-methylhistidine) and muscle protein turnover: An overview. Fed. Proc., 37, 2291-2230. 